\title{
EVALUASI KUALITAS PELAYANAN PERPUSTAKAAN DI SDN TEGALREJO MAGELANG JAWA TENGAH
}

\section{Ery Susilorini}

Progam Studi: S1 IImu Perpustakaan Universitas Terbuka

email: Rinisamantha33@gmail.com

\begin{abstract}
Abstrak
Kualitas layanan perpustakaan perpustakaan adalah kemampuan perpustakaan dalam mengelola perpustaakaan sehingga berdampak kepada peningkatan pengguna perpustakaan.Untuk meningkatkan agar siswa rajin dan menggunakan perpustakaan dengan baik maka tingkat pelayan perlu ditingkatkan.yaitu dengan menambah bahan koleksi dan mendesain tata ruang perpustakaan dengan baik, serta melalui promosi perpustakaan melalui brosur-brosur, sehingga terciptanys siswa gemar membaca. Penelitian ini bertujuan untuk melihat kinerja perpustakaan serta mengukur kepuasan pengguna perpustakaan di SDN Tegalrejo. Hasil riset membuktikan bahwa pelayanan yang dilakukan oleh Perpustakaan SDN Tegalrejo sudah cukup baik. Hal ini bisa dilihat dari grafik pengunjung dan peminjam mengalami peningkatan. Tersedianya cukup buku untuk dibaca, hal ini bisa dilihat dari koleksi buku di SDN Tegalrejo sudah mencapai 13.000 eksemplar. Dan pihak sekolah juga sudah menganggarkan dari dana BOS sebesar $25 \%$ tiap tahunnya.Adanya hambatan bagi perpustakaan untuk meningkatkan pelayanan siswa di SDN Tegalrejo yang disebabkan oleh adanya kesibukan siswa mengikuti kegiatan belajar mengajar, kurangnya waktu yang dimiliki siswa untuk mengunjungi perpustakaan dan kurangnya koleksi.Berdasarkan hasil penelitian, peneliti menyarankan agar pustakawan lebih banyak belajar yang berkaitan dengan cara mengelola perpustakaan dengan baik.
\end{abstract}

\section{A. PENDAHULUAN}

Perpustakaan sekolah adalah salah satu bagian dari kelengkapan sarana dan prasarana sekolah yang keberadaannya sangat membantu kegiatan peserta didik dan guru memperoleh informasi dari berbagai jenis bahan pustaka dengan membaca,mendengar dan sekaligus tempat petugas mengelola perpustakaan.Dengan adanya perpustakaan diharapkan berperan maksimal dalam upaya visi dan misi sekolah. Berdasarkan kasus di atas, maka penulis tertarik untuk mengadakan penelitian dengan judul "Evaluasi kualitas Pelayanan Perpustakaan SDN Tegalrejo".Kegiatan pengadaan dan perawatan bahan pustaka,peningkatan kualitas pelayanan bagi pemustaka dan kegiatan yang dapat menumbuhkembangkan minat membaca dan menulis merupakan 3 hal pokok dalam pengelolaan perpustakaan di SDN Tegalrejo.Menurut

\section{Kata kunci :}

Pelayanan perpustakaan, Kualitas perpustakaan
Martoatmojo (2009) perpustakaan sekolah memiliki beberapa fungsi, yaitu :

1. Fungsi Informasi, yaitu perpustakaan sebagai sumber informasi

2. Fungsi Pendidikan, membantu siswa memperjelas dan memperluas ilmu pengetahuan

3. Fungsi Rekreasi, dengan membaca novel ,pembaca dapat terhibur.

4. Fungsi Administrasi, kegiatan pengolahan bahan pustaka

5. Fungsi Pelestarian, menyimpan karya dari siswa maupun staf pengajar.

6. Fungsi Riset, membantu menyediakan bahan pustaka yang digunakan untuk penelitian.

Layanan yang baik harus dapat meberikan kesan yang baik,menarik dan dapat berguna bagi pengguna.Sedangkan tujuan layanan perpustakaan adalah membantu memenuhi kebutuhan 
pengguna akan informasi yang sesuai dengan kebutuhannya. Dalam uraian penelitian yang telah dibahas di atas, maka akan dilakukan penelitian meliputi:

1. layanan sirkulasi perpustakaan sekolah di SDN Tegalrejo

2. Pelayanan referensi perpustakaan sekolah di SDN Tegalrejo

3. Kinerja petugas perpustakaan sekolah SDN Tegalrejo

4. Hambatan perpustakaan sekolah dalam pelayanan di SDN Tegalrejo dan

5. Upaya perpustakaan sekolah dalam meningkatkan pelayanan di SDN Tegalrejo

\section{B. KAJIAN TEORITIS}

Menurut Huixin Chen (2018) tingkat layanan yang dipersonalisasi sangat penting untuk meningkatkan kualitas layanan perpustakaan, oleh karena itu perlu untuk mengevaluasinya berdasarkan metode yang efektif, salah satunya adalah hirarki analitik fuzzy yang diterapkan di dalamnya. Pertama, perlunya adanya pembahasan layanan perpustakaan yang dipersonalisasi. Kedua, perlunya analisis faktor-faktor yang mempengaruhi utama layanan personalisasi manajemen informasi perpustakaan, dan dibangun sistem indeks evaluasi. Ketiga, perlu dipelajari dan dirancang teori dasar proses hirarki analitik fuzzy, dan prosedur analisis. Akhirnya, enam perpustakaan digunakan sebagai contoh untuk melakukan analisis evaluasi, dan hasilnya menunjukkan bahwa hirarki analitik fuzzy adalah metode yang efektif untuk mengevaluasi tingkat layanan perpustakaan yang dipersonalisasi. Sementara menurut (Yan-Liang, Run-Fang, \& Xiao, 2017) saat ini semakin banyak produk elektronik telah diterapkan di perpustakaan, pada saat yang sama ada banyak faktor baru yang mempengaruhi kualitas layanan perpustakaan. Namun, tidak ada pengukuran yang lebih baik untuk mengidentifikasi mereka. Penetian ini mengkaji dan menyajikan sumber daya perpustakaan elektronik berdasarkan LibQUAL + dan Kano untuk membedakan faktorfaktor yang berpengaruh terhadap layanan perpustakaan di Universitas Zhengzhou. Pertama, LibQUAL + dan Kano termasuk 7 dimensi, yaitu kualitas interaktif, kegunaan, kepribadian, E-sumber daya, pengaruh perpustakaan, informasi layanan tradisional, diajukan model baru untuk menemukan potensi masalah yang mempengaruhi kualitas layanan elektronik perpustakaan. Kedua, peneliti ini merancang kuesioner kualitas layanan elektronik perpustakaan dan mendistribusikannya kepada siswa secara acak di perpustakaan Universitas Zhengzhou, dan memproses data menggunakan metode statistik. Akhirnya, layanan tambahan, platform komunikasi, dan informasi terbaru harus disediakan bagi pembaca. Selain itu, prinsip-prinsip TRIZ \# 1, \# 14, \# 19 diberikan untuk meningkatkan kualitas layanan sesuai dengan teknik-teknik TRIZ. Hasil menunjukkan bahwa model yang kami bangun layak melalui analisis empiris. Hasil studi ini menunjukkan, bahwa penelitian ini dilakukan untuk mengidentifikasi masalah kualitas layanan dengan mewawancarai pembaca. Dimensi LibQUAL + yang terintegrasi dengan 24 kriteria dari model Kano digunakan sebagai pedoman untuk survei dan mengukur kualitas layanan perpustakaan. Menurut demonstrasi di atas, kualitas layanan perpustakaan berdampak pada kepuasan pembaca, menggunakan prinsip-prinsip inventif TRIZ \# 1, \# 14, \# 19 untuk menyelesaikan masalah-masalah ini menyediakan cara berpikir sistematis yang unik. Solusi tersebut menyarankan bahwa perpustakaan harus menyediakan layanan tambahan, meningkatkan komunikasi dengan pembaca, dan memastikan informasi selalu lengkap, dengan meningkatkan kualitas layanan perpustakaan untuk meningkatkan kepuasan pembaca. Adapun hasil dalam demonstrasi, kepuasan sederhana dari layanan elektronik perpustakaan Universitas Zhengzhou adalah negatif, yang menunjukkan kualitas layanan tidak 
dapat memenuhi kebutuhan pembaca, oleh karena itu, perpustakaan memiliki ruang besar untuk meningkatkan kualitas perpustakaan elektronik. Pertama-tama, perpustakaan harus memasukkan uang ke dalam peningkatan kualitas yang diperlukan berdasarkan hasil pengakuan atribut kualitas. Kedua, perpustakaan harus mempertimbangkan untuk meningkatkan kualitas satu dimensi karena kepuasan sebanding dengan fungsi: ketika fungsi tersebut akan berlipat ganda, kepuasan pengguna yang terkait digandakan. Ketiga, perpustakaan dapat sangat meningkatkan kepuasan pembaca melalui peningkatan kualitas yang menarik. Akhirnya, perpustakaan dapat meningkatkan kualitas acuh tak acuh ketika investasi cukup, karena tidak ada kontribusi yang jelas untuk kepuasan pembaca ketika kualitas acuh tak acuh telah berubah secara fungsional.

\section{METODE PENELITIAN}

Penelitian ini dilakukan di perpustakaan sekolah SDN Tegalrejo daritanggal 1 Oktober sampai dengan tanggal 25 Oktober 2019. Teknik pengumpulan data dengan mengadakan wawancara. Penulis bisa langsung mendapatkan hasil melalui bercakap-cakap dan bertatap muka dengan orang yang dapat memberikan keterangan dalam mendapat data. Wawancara akan dilakukan dengan perwakilan perkelas 1 siwa.Kelas 1 diwakili Abi Niscala Okto; Kelas 2 diwakili Kanza; Kelas 3diwakili Salsabila; Kelas 4diwakili Nathaniela; Kelas 5 diwakili Ersaf Arifin; dan Kelas 6 diwakili oleh Firdha. Selain wawancara, pengumpulan data dilakukan dengan observasi partisipasi, yakni mengadakan pengamatan secara langsung dilapangan tempat penelitian dengan cara mencatat data nyata sehingga memperoleh informasi yang dibutuhkan. Pengumpulan data lainnya bersumber dari studi dokumentasi, yaitu dengan mencatat data/informasidari literatur yang berhubungan dengan pengguna perpustakaan.

\section{HASIL DAN PEMBAHASAN}

Hasil dari wawancara dan observasi yang terkumpul tersebut dirangkum, dan dianalisa untuk segera ditindak lanjuti. Kemudian penulis melakukan observasi penelitian yaitu :

1. layanan sirkulasi perpustakaan sekolah di SDN Tegalrejo meliputi kegiatan peminjaman baca di tempat peminjaman buku,dan pengembalian buku

2. layanan referensi perpustakaan sekolah di SDN Tegalrejo,adalah kegiatan memberikan informasi-informasi yang dibutuhkan oleh siswa mengenai koleksi bahan perpustakaan dan memberikan bimbingan belajar dan membaca kepada siswa dengan bekerjasama dengan guru kelas.

3. kinerja petugas perpustakaan di SDN Tegalrejo berusaha meningkatkan kemampuannya melalui diklat untuk meningkatkan kompetensi yang dimiliki dalam bidang perpustakaan.

4. kendala perpustakaan untuk meningkatkan pelayanan siswa di SDN Tegalrejo adalah adanya,kurangnya waktu yang dimiliki siswa untuk mengunjungi perpustakaan dan kurangnya koleksi buku fiksi bergambar dan ensiklopedia.

5. Usaha perpustakaan untuk meningkatkan pelayanandi SDN Tegalrejo adalah dengan menggunakan sistem pelayanan secara terbuka yaitu pengguna perpustakaan bisa langsung mencari ke tempat rak buku dan bisa mengambil buku sendiri.

6. Untuk memperlancar kegiatan pelayanan perpustakaan dengan penjajaran koleksi berdasarkanwarna sampul,skotlet buku,besar kecil buku,punggung buku dan call number,yaitu:

a). Disamakan warna skotlet masing masing buku yang ada pada punggung buku. 
b). Penyusunan buku di mulai dari kiri ke kanan dan buku yang ukuran kecil ke buku besar.

Untuk mengevaluasi layanan sirkulasi yang erat kaitannya dengan kepuasan pengguna,kinerja pustakawan dan relevansi bahan pustaka yang ada dengan kebutuhan pemakai perpustakaan, maka perlu diadakan penggalian data yang dapat dilakukan dengan menggunakan wawancara langsung dengan siswa. Selain itu dapat juga dengan melihat perbandingan statistik selama beberapa tahun terakhir. Karena data-data yang ada menunjukkan kinerja perpustakaan yang kemudian dianalisa penyebabnya (Basuki, 2010, p. 297).

Dengan meningkatkan kualitas pelayanan maka pengunjung dan peminjaman perpustakaan di SDN Tegalrejo semakin meningkat dibuktikan dengan hasil rekapitulasi tiap tahunnya, sebagaimana disajikan pada tabel-tabel beikut.

Tabel 1

Rekapitulasi pengunjung SDN Tegalrejo

Tahun Ajaran 2016/ 2017

\begin{tabular}{|c|c|c|c|c|c|c|c|c|c|c|c|c|}
\hline \multirow{2}{*}{ Kelas } & \multicolumn{10}{|c|}{ Jumlah Pengunjung } \\
\cline { 2 - 16 } & Jan & Feb & Mar & Apr & Mei & Jun & Jul & Agus & Sep & Okt & Nov & Des \\
\hline 1 & 73 & 47 & 31 & 33 & 31 & 36 & 35 & 29 & 83 & 64 & 63 & 39 \\
\hline 2 & 41 & 63 & 28 & 25 & 33 & 18 & 26 & 25 & 91 & 36 & 68 & 49 \\
\hline 3 & 63 & 39 & 32 & 26 & 26 & 31 & 29 & 23 & 125 & 87 & 123 & 26 \\
\hline 4 & 45 & 57 & 37 & 54 & 92 & 71 & 56 & 55 & 113 & 60 & 75 & 105 \\
\hline 5 & 84 & 37 & 61 & 70 & 52 & 39 & 121 & 86 & 153 & 90 & 64 & 38 \\
\hline 6 & 64 & 29 & 24 & 52 & 34 & 38 & 44 & 35 & 95 & 106 & 102 & 17 \\
\hline Jml & 370 & 272 & 203 & 260 & 268 & 233 & 267 & 253 & 660 & 443 & 495 & 274 \\
\hline
\end{tabular}

Sumber data dari Perpustakaan SDN Tegalrejo

Pada Tabel 1, tampak bahwa tingkat pengunjung siswa SDN Tegalrejo mengalami fluktuasi (naik turun) dari bulan ke bulan. Tingkat kunjungan tertinggi terjadi pada bulan September (660 siswa) dan terendah kunjungan bulan Maret (203 siswa). Total jumlah pengunjung tahun ajaran 2016/2017 adalah 4.008 siswa.Kenapa pada bulan September terjadi banyak pengunjung karena siswa selesai melaksanakan tes semesteran, setelah selesai semesteran ada jeda semester jadi anak anak belum mendapat pelajaran secara penuh. dan kenapa di bulan Maret terjadi penurunan pengunjung ke perpustakaan karena di bulan Maret banyak kegiatan untuk persiapan ujian kelas 6 .

Tabel 2

Rekapitulasi pengunjung perpustakaan SDN TegalrejoTahun ajaran 2017/2018

\begin{tabular}{|c|c|c|c|c|c|c|c|c|c|c|c|c|}
\hline \multirow{2}{*}{ Kelas } & \multicolumn{10}{|c|}{ Jumlah Pengunjung } \\
\cline { 2 - 16 } & Jan & Feb & Mar & Apr & Mei & Jun & Jul & Agu & Sep & Okt & Nov & Des \\
\hline 1 & 65 & 81 & 69 & 70 & 45 & 65 & 84 & 72 & 96 & 60 & 92 & 84 \\
\hline 2 & 56 & 92 & 59 & 95 & 70 & 67 & 66 & 69 & 122 & 93 & 56 & 64 \\
\hline 3 & 59 & 73 & 68 & 66 & 49 & 81 & 76 & 67 & 128 & 59 & 38 & 96 \\
\hline 4 & 96 & 69 & 48 & 59 & 42 & 83 & 53 & 84 & 138 & 73 & 76 & 56 \\
\hline 5 & 66 & 101 & 42 & 86 & 36 & 87 & 62 & 63 & 117 & 69 & 46 & 59 \\
\hline 6 & 32 & 87 & 69 & 91 & 88 & 76 & 70 & 53 & 110 & 29 & 25 & 70 \\
\hline Jml & 374 & 503 & 355 & 467 & 330 & 459 & 411 & 408 & 711 & 383 & 333 & 429 \\
\hline
\end{tabular}

Sumber data dari perpustakaan SDN Tegalrejo

Pada Tabel 2, tampak bahwa tingkat pengunjung siswa SDN Tegalrejo mengalami fluktuasi (naik turun) dari bulan ke bulan. Tingkat kunjungan tertinggi terjadi pada bulan September (711 siswa) dan terendah kunjungan bulan Mei (330 siswa).Kenapa pada bulan September terjadi banyak pengunjung karena siswa habis melaksanakan tes semesteran, setelah selesai semesteran ada jeda semester, jadi anak anak belum mendapat pelajaran secara penuh sehingga lebih banyak waktu untuk mengunjungi dan kenapa di bulan Mei terjadi penurunan pengunjung ke perpustakaan karena di bulan Mei banyak kegiatan untuk persiapan ujian kelas 6 .

Diagram pengunjung perpustakaan SDN Tegalrejo

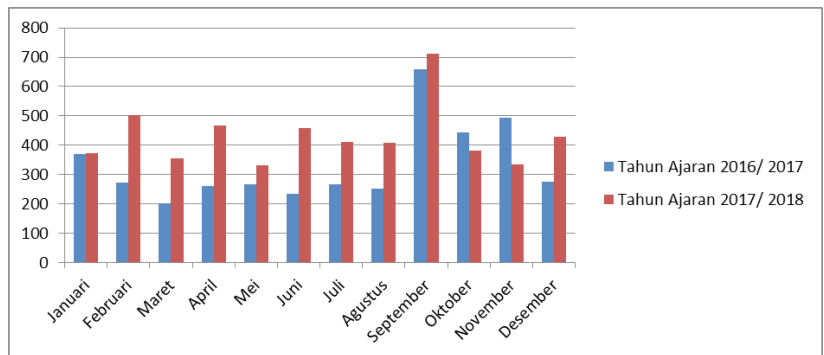

Jumlah pengunjung perpustakaan SDN Tegalrejo tahun ajaran 2017/2018 adalah 5.163 
siswa. Dari hasil analisis Tabel 1 dan Tabel 2 diatas dapat disimpulkan bahwa pengunjung di Perpustakaan SDN Tegalrejo mengalami peningkatan, dari 4.008 menjadi 5.163 siswa.

Tabel 3

Rekapitulasi Peminjam buku Di SDN

TegalrejoTahun ajran 2016/2017

\begin{tabular}{|c|c|c|c|c|c|c|c|c|c|c|c|c|}
\hline \multirow{2}{*}{ Kelas } & \multicolumn{10}{|c|}{ Jumlah Peminjam } \\
\cline { 2 - 15 } & Jan & Feb & Mar & Apr & Mei & Jun & Jul & Agu & Sep & Okt & Nov & Des \\
\hline 1 & 26 & 11 & 19 & 14 & 16 & 21 & 23 & 15 & 13 & 25 & 18 & 15 \\
\hline 2 & 37 & 24 & 31 & 24 & 32 & 15 & 19 & 22 & 26 & 31 & 12 & 9 \\
\hline 3 & 33 & 12 & 29 & 19 & 29 & 9 & 21 & 36 & 21 & 26 & 19 & 11 \\
\hline 4 & 12 & 35 & 33 & 39 & 18 & 11 & 14 & 15 & 19 & 24 & 22 & 16 \\
\hline 5 & 29 & 18 & 23 & 26 & 14 & 19 & 11 & 38 & 13 & 32 & 25 & 13 \\
\hline 6 & 24 & 35 & 13 & 31 & 21 & 13 & 9 & 25 & 26 & 29 & 15 & 19 \\
\hline Jml & 161 & 135 & 148 & 153 & 130 & 88 & 97 & 151 & 118 & 157 & 111 & 83 \\
\hline
\end{tabular}

Sumber data dari perpustakaan SDN Tegalrejo

Pada Tabel 3, tampak bahwa tingkat peminjam buku siswa SDN Tegalrejo mengalami fluktuasi (naik turun) dari bulan ke bulan. Tingkat peminjam tertinggi terjadi pada bulan Januari (161 siswa) dan terendah peminjam bulan Juni (88 siswa). Penurunan peminjaman buku terjadi pada bulan Juni dikarenakan libur kenaikan kelas. Total jumlah peminjam perpustakaan SDN Tegalrejo tahun ajaran 2016/2017 adalah 1.532 siswa.

Tabel 4

Rekapitulasi Peminjam buku di Perpustakaan SDN TegalrejoTahun ajaran 2017/2018

\begin{tabular}{|c|c|c|c|c|c|c|c|c|c|c|c|c|}
\hline \multirow{2}{*}{ Kelas } & \multicolumn{10}{|c|}{ Jumlah Peminjam } \\
\cline { 2 - 16 } & Jan & Feb & Mar & Apr & Mei & Jun & Jul & Agu & Sep & Okt & Nov & Des \\
\hline 1 & 36 & 17 & 35 & 20 & 22 & 27 & 28 & 23 & 21 & 33 & 27 & 24 \\
\hline 2 & 43 & 32 & 36 & 31 & 38 & 22 & 23 & 30 & 34 & 39 & 31 & 18 \\
\hline 3 & 39 & 18 & 35 & 21 & 35 & 15 & 17 & 43 & 29 & 34 & 28 & 21 \\
\hline 4 & 18 & 41 & 39 & 45 & 24 & 17 & 18 & 22 & 27 & 32 & 31 & 26 \\
\hline 5 & 35 & 24 & 29 & 32 & 21 & 25 & 26 & 45 & 34 & 40 & 34 & 32 \\
\hline 6 & 31 & 42 & 19 & 37 & 27 & 19 & 31 & 32 & 21 & 37 & 24 & 29 \\
\hline Jml & 202 & 174 & 193 & 186 & 167 & 125 & 143 & 195 & 166 & 215 & 165 & 150 \\
\hline
\end{tabular}

Sumber data dari perpustakaan SDN Tegalrejo

Pada Tabel 4, tampak bahwa tingkat peminjam buku siswa SDN Tegalrejo mengalami fluktuasi (naik turun) dari bulan ke bulan. Tingkat peminjam terbanyak terjadi pada bulan November (215 siswa) dan terendah peminjam bulan Juni (125 siswa). Kenapa dibulan Juni peminjaman menurun karena di bulan Juni adalah libur sekolah kenaikan kelas .Total jumlah peminjam perpustakaan SDNTegalrejo tahun ajaran 2017/2018 adalah 2.081 siswa.

Diagram peminjaman buku Perpustakaan SDN Tegalrejo

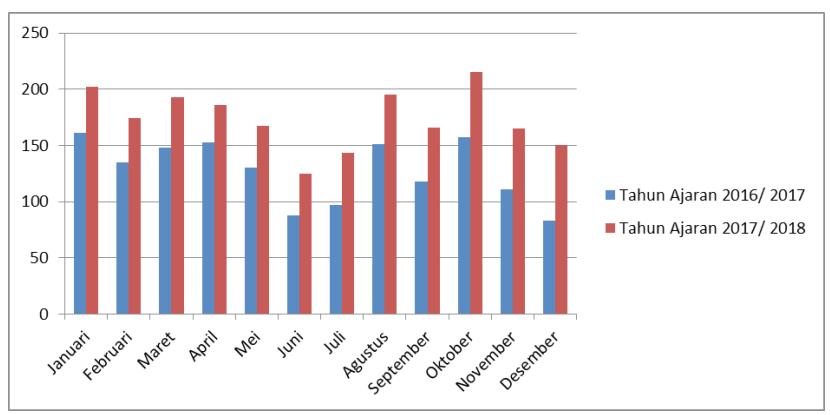

Jumlah peminjam di SDN Tegalrejo tahun ajaran 2017/2018 adalah 2.081siswa. Dari hasil analisis Tebl 3 dan Tabel 4 diatas dapat disimpulkan bahwa jumlah peminjam di SDN Tegalrejo mengalami peningkatan, dari 1.532 menjadi 2.081 siswa .

Dari hasil tabel dan diagram diatas dapat disimpulkan bahwa dengan pelayanan yang baik dan ramah dapat memberikan energi positif untuk siswa semakin rajin berkunjung dan memanfaatkan perpustakaan dengan maksimal.

\section{E. PENUTUP}

\section{Simpulan}

Dari hasil kajian ini dapat rumuskan sebuah kesimpulan, bahwa

1. Pelayanan yang dilakukan oleh perpustakaan SDN Tegalrejo sudah baik.Hal ini bisa dilihat dari grafik pengunjung dan peminjam mengalami peningkatan.

2. Tersedianya cukup buku untuk dibaca,hal ini bisa dilihat dari koleksi buku di SDN Tegalrejo sudah mencapai 13.000 eksemplar.Dan pihak sekolah juga sudah menganggarkan daridana BOS sebesar $25 \%$ tiap tahunnya.

3. Adanya hambatan bagi perpustakaan untuk meningkatkan pelayanan siswa di SDN Tegalrejo yaitu kurangnya kesadaran tentang kurangnya manfaat perpustakaan 


\section{Saran}

Sementara berdasarkan hasil penelitian maka disarankan kepada :

1. Pimpinan untuk menambah petugas perpustakaan, terus menerus menambah koleksi bahan pustaka fiksi

2. Pustakawan hendaknya mengetahui kebutuhan pengguna dan bisa menciptakan suasana nyaman dan menyenangkan

3. Guru kelas supaya memberdayakan perpustakaan untuk membantu dalam proses pembelajaran siswa.

\section{DAFTAR PUSTAKA}

Basuki, S. (2010). Pengantar Ilmu Perpustakaan. Jakarta: Gramedia Pustaka Utama.

Chen, H. (2018). Evaluation of Personalized Service Level for Library Information Management Based on Fuzzy Analytic Hierarchy Process. Procedia Computer Science, 131, 952-958.

Yan-Liang, Run-Fang, Z., \& Xiao, M. (2017). Studying on Enhancing Readers. Satisfaction Model of Electronic Service Quality in Library Based on LibQUAL+ and Kano. Procedia Engineering, 174, 160-266. 